\title{
Photodegradation of Rhodamine 6G Molecules Using $\mathrm{TiO}_{2}$ Photocatalyst
}

\author{
Nafie A. Almuslet ${ }^{*}$ and Mohammed A. Baba \\ * Institute of laser-Sudan University of Science and Technology (www.sustech.edu \&Email: \\ nafiealmuslet@sustech.edu),Khartoum / Republic of Sudan, P. O. Box (407),
}

\begin{abstract}
In this work the photodegradation of Rhodamine $6 G$ was studied by adding different amounts of semiconductor $\left(\mathrm{TiO}_{2}\right)$, as a photocatalyst, to fixed concentration of Rhodamine $6 \mathrm{G}$ in water and the mixture was irradiated by UV light in the range from 270 to $280 \mathrm{~nm}$. The UV light has energy of $750 \mathrm{~mJ}$ and spot size of $4 \mathrm{~cm}^{2}$ and the irradiation was done in different exposure times.The absorption spectra of Rhodamine $6 G$ with different amounts of catalyst, before and after irradiation, were recorded and compared. The results showed that the efficiency of the photodegradation process was increased with increasing the amount of semiconductor $\left(\mathrm{TiO}_{2}\right)$ and irradiation time. The percentage of Rhodamine $6 \mathrm{G}$ degradation was $16 \%$ when $100 \mathrm{mg}$ of $\mathrm{TiO}_{2}$ was added and irradiated for 10 min, while $82 \%$ of Rhodamine $6 \mathrm{G}$ was removed when $600 \mathrm{mg}$ of $\mathrm{TiO}_{2}$ was added and irradiated for 30 min.This study concluded that the degradation of Rhodamine $6 G$ is increased with increasing the amount of semiconductor $\left(\mathrm{TiO}_{2}\right)$ and with increasing the irradiation time.
\end{abstract}

Keywords: photocatalysis, photodegradation, Rhodamine $6 \mathrm{G}, \mathrm{TiO}_{2}$.

\section{Introduction}

The word photocatalysis is a composite word which is composed of two parts, "photo" and "catalysis". Catalysis is the process where a substance participates in modifying the rate of a chemical transformation of the reactants without being altered or consumed in the end. This substance is known as the catalyst which increases the rate of a reaction by reducing the activation energy[1].

Generally, photocatalysis is a reaction which uses light to activate a substance which modifies the rate of a chemical reaction without being involved itself. In other words, the photocatalyst is the substance which can modify the rate of chemical reaction using light irradiation without being altered or consumed in the end $[2,3]$. Toxicology and carcinogenesis studies of Rhodamine $6 \mathrm{G}$ were conducted because of potential human exposure resulting from it when used as a dye for natural and synthetic fibers and in biomedical research and because of the absence of information on Rhodamine $6 \mathrm{G}$ toxicity and potential carcinogenicity. Rohdamine $6 \mathrm{G}$ can cause severe eye irritation, respiratory tract and skin irritation, might be harmful if absorbed through skin or if swallowed, may be harmful if inhaled, and the laboratory tests indicate that this material may be carcinogenic. Rhodamine 6G is toxic to eukaryotic cell mitochondria and it depending on cellular concentration. In two-stage skin models of carcinogenesis, activation of protein kinas' $\mathrm{C}$ by a promoter, such as 12-0-tetradecanoylphorbol- 13-acetate (TPA), it is considered to be an integral event associated with the promotion and development of skin neoplasms (papillomas or carcinomas). O'Brian and Weinstein in (1987) found that Rhodamine 6G inhibited rat brain protein kinas' $\mathrm{C}$ after activation with the tumor promoter TPA, presumably through a chemical-lipid interaction and the induction of cytotoxicity, but not in the absence of lipid cofactor. There is no reported evidence that Rhodamine 6G inhibits protein kinas' $\mathrm{C}$ isolated from epidermal cells. However, inhibition of rat brain protein kinas' $\mathrm{C}$ in vitro suggests Rhodamine $6 \mathrm{G}$ should not induce skin neoplasms or promote spontaneously occurring skin neoplasm's [4,5].

The aims of this work are:

$>$ To study the effect of the amount of $\mathrm{TiO}_{2}$ on the process of photodegradation of Rhodamine $6 \mathrm{G}$ in waste water.

$>$ To study the effect of the exposure time of UV light on the process of photodegradation of Rhodamine $6 \mathrm{G}$ in waste water.

\section{Materials and Methods:}

The samples under study were prepared by dissolving $7 \mathrm{mg}$ from Rhodamine $6 \mathrm{G}$ in $100 \mathrm{ml}$ of distilled water then $100 \mathrm{mg}$ of the catalyst $\left(\mathrm{TiO}_{2}\right)$ was added to the first sample.Similarly300mg from the same semiconductor was added to the second sample and finally $600 \mathrm{mg}$ of $\mathrm{TiO}_{2}$ was added to the third sample. After that, a small portion ofthe first sample was put in quartz cell and placed in the compartment of the UV spectrometer and the absorption spectrum was recorded and used as reference.Similarly this step was repeated for the second and the third samples, separately. 
The first sample was irradiated with $750 \mathrm{~mJ}$ of UV light with wavelengths of (270-280 nm) and spot size of $4 \mathrm{~cm}^{2}$ for 10 minutes, then the absorption spectrum of this sample was recorded using the UV spectrometer. The above step was repeated with irradiation time of 20 and 30 minutes. The absorption spectra were recorded for the two cases. The above steps were repeated for samples two and three. The effects of $\mathrm{TiO}_{2}$ amount and irradiation times were deduced from the comparison between the intensity of the absorption bands of Rhodamine $6 \mathrm{G}$ in each case.

Figure (1) shows a schematic diagram of the setup arrangement.

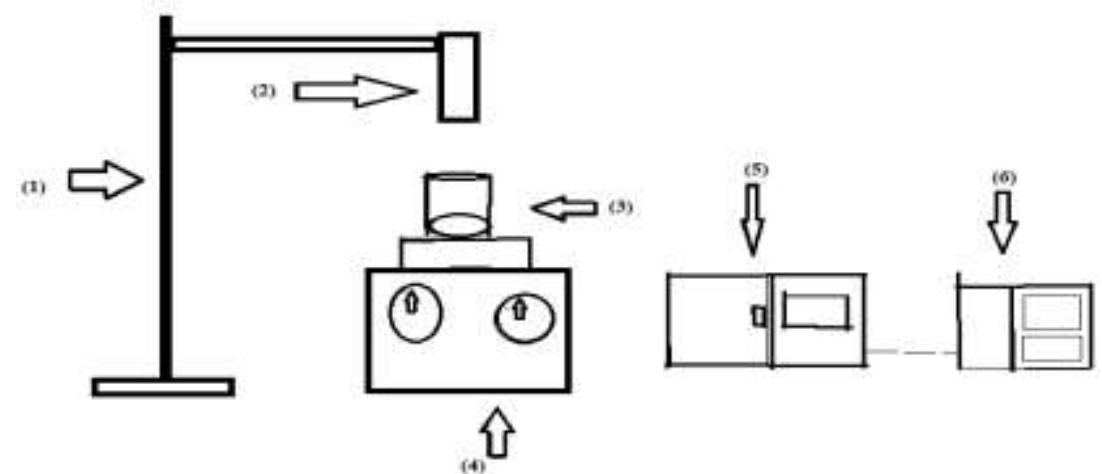

Figure (1): Schematic diagram of setup used in this work

(1) Holder, (2) The UV light source, (3) the glass beaker, (4) Themagnetic stirrer, (5) The UV/Vis. spectrometer and (6) The printer.

\section{Results:}

The results are classified into two categories:The effect of the amount of the semiconductor and The dependence of the degradation of Rhodamine $6 \mathrm{G}$ on the irradiation time.

The absorption spectrum of Rhodamine $6 \mathrm{Gin} 100 \mathrm{ml}$ of water without irradiation:

Figure (2) shows the absorption spectrum of Rhodamine 6G without addition of semiconductor and without irradiation. It can be observed in the figure a strong absorption band at $525 \mathrm{~nm}$.

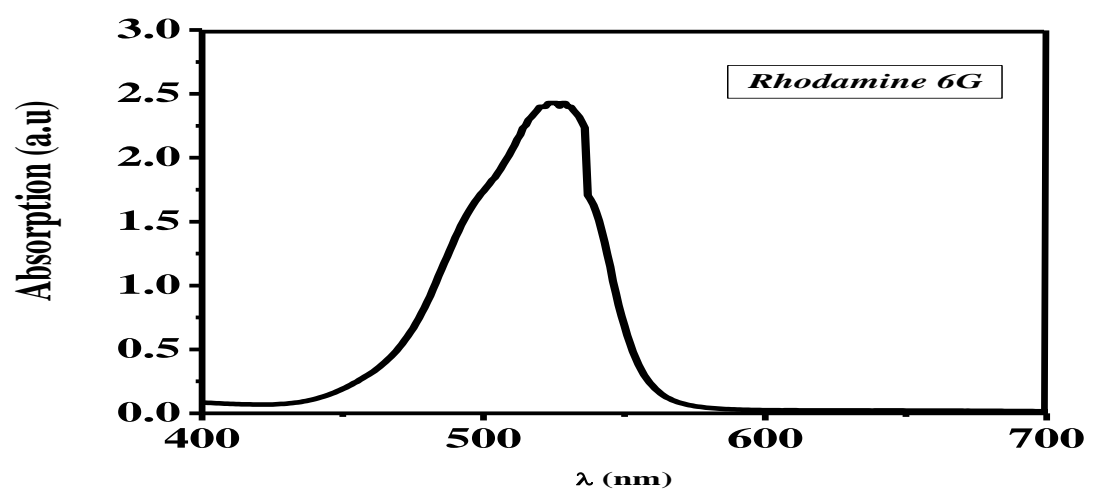

Figure (2): The absorption spectrum of Rhodamine6G without irradiation and semiconductor

The Absorption spectra of Rhodamine 6G mixed with $100 \mathrm{mg}$ of $\mathrm{TiO}_{2}$ irradiated by UV light source for different times:

Figure (3) shows the absorption spectra of Rhodamine 6G mixed with $100 \mathrm{mg}$ of $\mathrm{TiO}_{2}$ at different exposure times. 


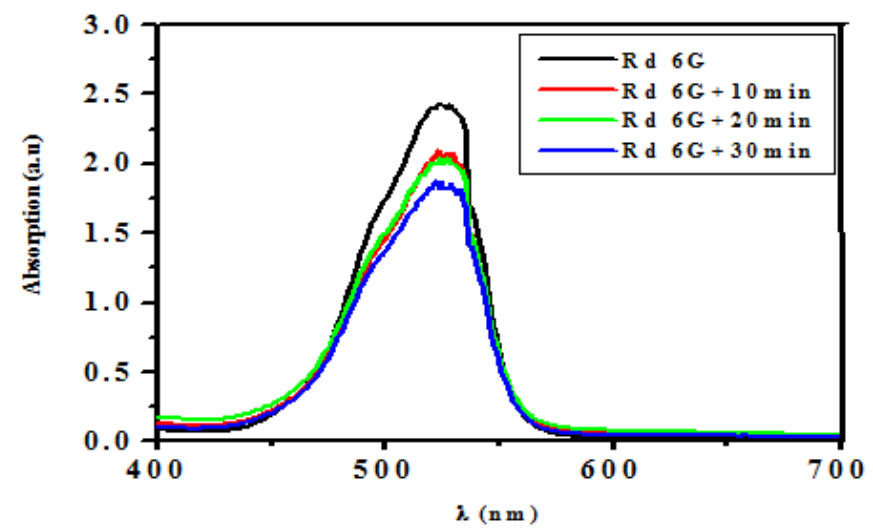

Figure (3): The absorption spectra of Rhodamine $6 \mathrm{G}$ mixed with $100 \mathrm{mg}$ of $\mathrm{TiO}_{2}$ irradiated by UV light for different exposure times

It can be observed from figure (3) that the intensity of the absorption peak of Rhodamine $6 \mathrm{G}$ at $525 \mathrm{~nm}$ is not significantly decreased with increasing the irradiation time.

Figure (4) shows the effect of irradiation times of the UV light on the ratio of the amount of Rhodamine 6G after and before irradation.

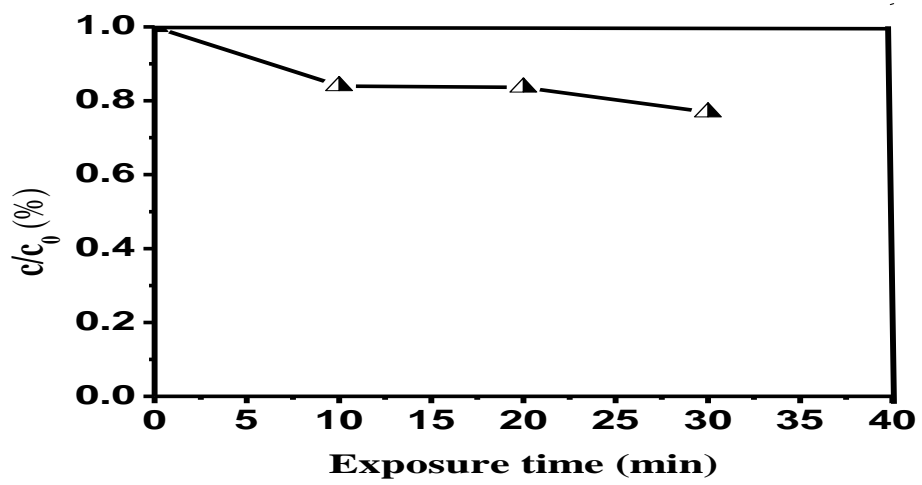

Figure (4): The effect of exposure time on the ratio of the amount of Rhodamine 6G after and before irradation

Fromfigure (4) it can seen that the exposure time was slightly affect the ratio between the amount ofRhodamine $6 \mathrm{G}$ after and before irradation when the catalyst was $100 \mathrm{mg}$ only.

The absorption spectra of Rhodamine $6 \mathrm{G}$ mixed with $300 \mathrm{mg}$ of $\mathrm{TiO}_{2}$ irradiated by UV light for different times:

The absorption spectra of Rhodamine $6 \mathrm{G}$ mixed with $300 \mathrm{mg}$ of $\mathrm{TiO}_{2}$, after irradiation for different exposure times, are shown in figure (5). The effect of the irradiation time on the degradation of Rhodamine $6 \mathrm{G}$ can be noticed through the decrease of the absorption intensity of Rhodamine $6 \mathrm{G}$ at $525 \mathrm{~nm}$ with time increasing.

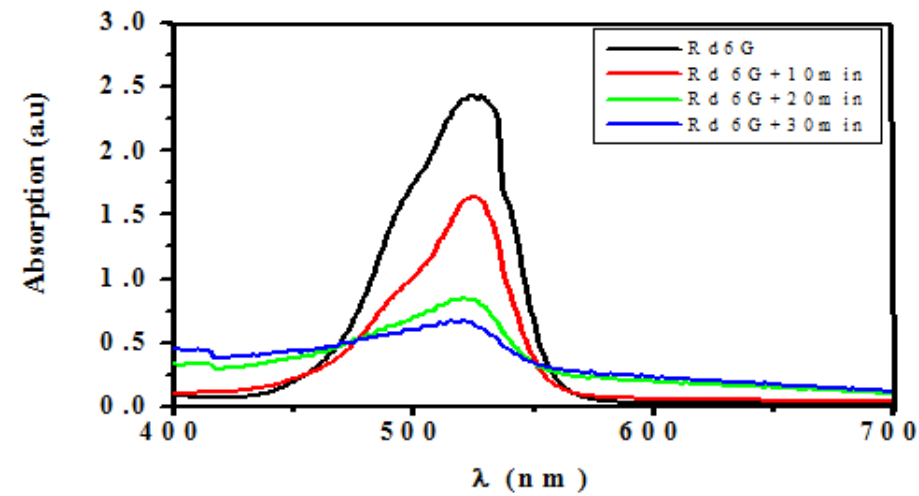

Figure (5): The absorption spectra of Rhodamine $6 \mathrm{G}$ mixed with $300 \mathrm{mg}$ of $\mathrm{TiO}_{2}$ irradiated by UV light for different times 
Figure (6) shows the effect of irradiation times of UV light on the ratio between the amount of Rhodamine 6G after and before irradation.

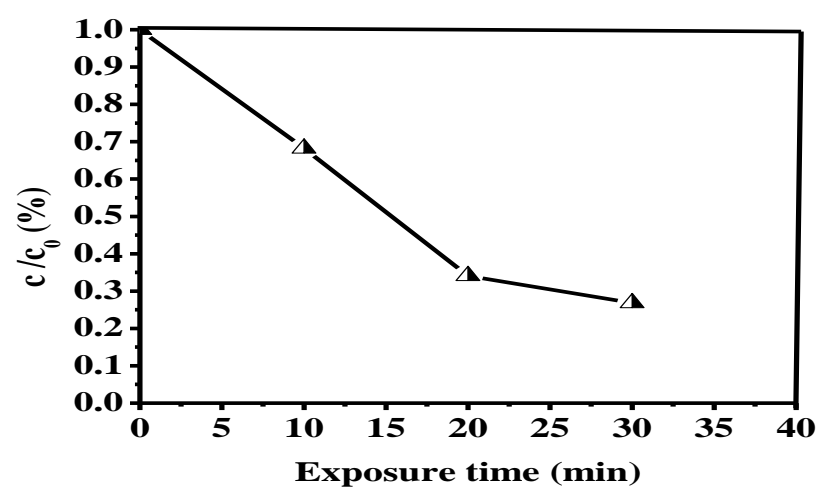

Figure (6) The ratio between the amount of Rhodamine $6 \mathrm{G}$ after and before irradation mixed with $300 \mathrm{mg}$ of $\mathrm{TiO}_{2}$ and irradiated for different exposure times.

One can noticed that the ratio of the amount of Rhodamine6G after and before irradation was decreased significantly with the increasing of expoure times when $300 \mathrm{mg}$ of $\mathrm{TiO}_{2}$ was used.

The absorption spectra of Rhodamine $6 \mathrm{G}$ mixed with $600 \mathrm{mg}$ of $\mathrm{TiO}_{2}$ irradiated by $\mathrm{UV}$ light source for different times:

Figure (7) shows the absorption spectra of the Rhodamine $6 \mathrm{G}$ mixed with $600 \mathrm{mg} \mathrm{of} \mathrm{TiO}_{2}$ after irradiation with different exposure times, The effect of the irradiation time on the degradation of Rhodamine $6 \mathrm{G}$ can be noticed through the decrease of the absorption intensity at $525 \mathrm{~nm}$.

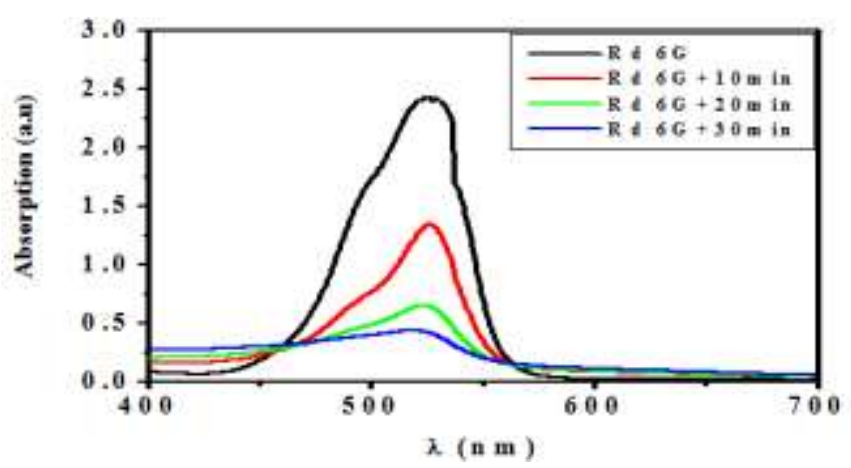

Figure (7): The absorption spectra of Rhodamine $6 \mathrm{G}$ mixed with $600 \mathrm{mg}$ of $\mathrm{TiO}_{2}$ irradiated by $\mathrm{UV}$ light for different exposure times.

Figure (8) shows the effect of irradiation times of UV light on the ratio between the amount of Rhodamine 6G after and before irradation.

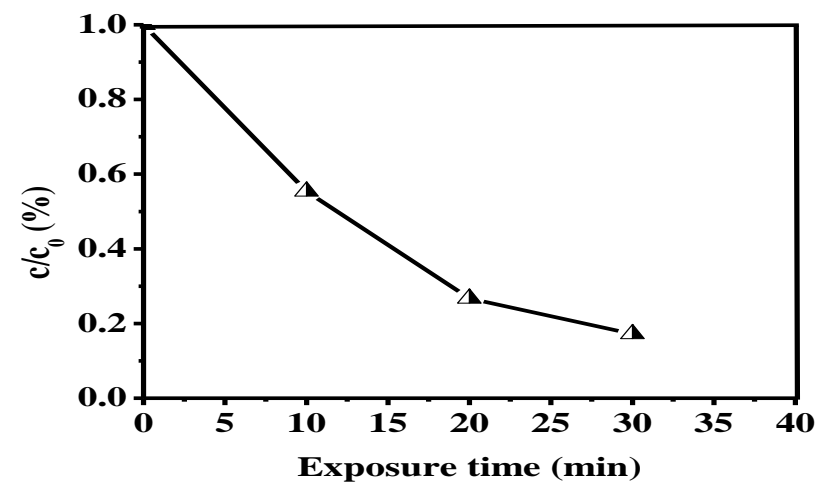

Figure (8): The ratio between the amount of Rhodamine $6 \mathrm{G}$ after and before irradation mixed with $600 \mathrm{mg}$ of $\mathrm{TiO}_{2}$ and irradiated for different exposure times. 
As can be seen from figure (8) the ratio of the amount of Rhodamine $6 \mathrm{G}$ after and before irradation is approximatly decay too muchwith $30 \mathrm{~min}$. irradiation time.

Comparison of the degradation rate of Rhodamine 6G with different irradiation times and different $\mathrm{TiO}_{2}$ weights:

Figure (9) shows the degradation percentage of Rhodamine 6G at different exposures times and different wieghts of $\mathrm{TiO}_{2}$.

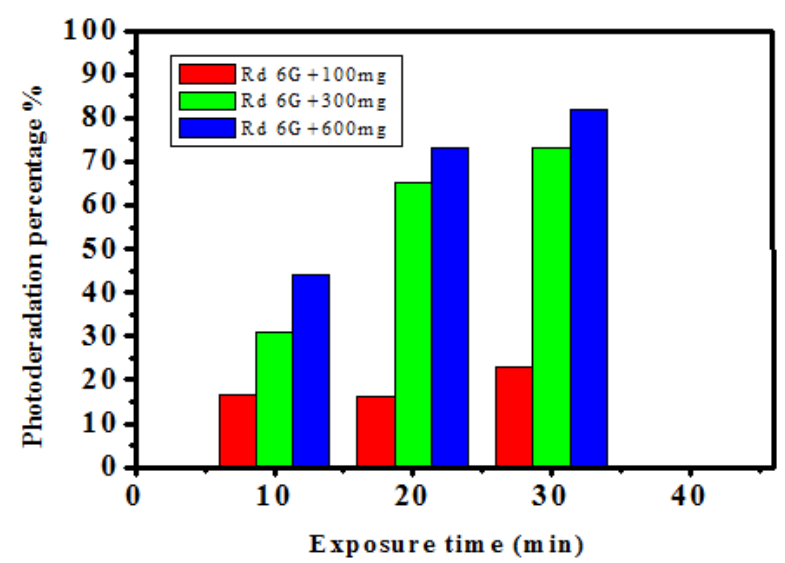

Figure (9): The degradation percentage of Rhodamine $6 \mathrm{G}$ at different exposure times with different wieght of $\mathrm{TiO} 2$ catalyst.

\section{Discussion:}

The photodegradation percentage of Rhodamine6G mixed with $100 \mathrm{mg}$ of $\mathrm{TiO}_{2}$ was $16 \%$ when irradiated for 10 minutes and it was slightly increased to $16.5 \%$ when irradiated for 20 minutes and finally increased to $23 \%$ at 30 minutes . The amount of $\mathrm{TiO}_{2}$ mixed with Rhodamine6G and the exposure time are not efficient for photodegradation process in this case.

For the case of Rhodamine $6 \mathrm{G}$ mixed with $300 \mathrm{mg}$ of $\mathrm{TiO}_{2}$ shown in figure (5), one can see that the number of Rhodamine6G molecules absorbing light is decreased significantly. The percentage of photodegradation process was increased to $31 \%, 65 \%$ and $73 \%$ at 10,20 and 30 minutes, respectively.

As it can observed from figure (7), the absorption spectra of $\mathrm{Rd} 6 \mathrm{G}$ mixed with $600 \mathrm{mg}$ of $\mathrm{TiO}_{2}$ showed the highest decreasing of $\mathrm{Rd} 6 \mathrm{G}$ and there was a significant increase in the percentage of photodegradation process which was $43 \%$ when irradiated for 10 minutes, $73 \%$ for 20 min and was $82 \%$ for 30 minutes. The photodegradation process for $\mathrm{Rd} 6 \mathrm{G}$ mixed with $600 \mathrm{mg}$ of $\mathrm{TiO}_{2}$ was more efficient than those with $100 \mathrm{mg}$ and $300 \mathrm{mg}$.

These results are in agreement with the results of M. Qamar, M.A. Gondal, and Z.H. Yamani [6], where they studied the removal of $\mathrm{Rd} 6 \mathrm{G}$ induced by laser and $\mathrm{WO}_{3}$ nanocomposite, and the results of Tanmay $\mathrm{K}$. Ghorai, NiladriBiswas [7], in their studies of photodegradation of $\mathrm{Rd} 6 \mathrm{G}$ in aqueous solution via $\mathrm{SrCrO}_{4}$ and $\mathrm{TiO}_{2}$ nano-sphere mixed oxides. Moreover, here is a good agreement with the results of AshishBansal, Deependar Sharma, RakshitAmetaand Hari S. Sharmawhere they studied the photodegradation of rhodamine-6G in presence of ammonium phosphomolybdate and the results of Sandip P. Patila, V.S. Shrivastava\& G.H. Sonawanewhere they studied the Photocatalytic degradation of Rhodamine $6 \mathrm{G}$ using $\mathrm{ZnO}$ montmorillonitenanocomposite [8,9].

\section{Conclusions}

From the results obtained in this work the followings can be conclude that:

1. The degradation of Rhodamine $6 \mathrm{G}$ increased with the increasing of exposure time.

2. The degradation of Rhodamine $6 \mathrm{G}$ increased with the increasing of semiconductor weight.

3. The degradation is very efficient in the case of Rhodamine $6 \mathrm{G}$ mixed with $600 \mathrm{mg} \mathrm{TiO}_{2}$ irradiated with $\mathrm{UV}$ light for 30 minutes.

\section{References:}

[1]. M. A. Fox and M. T. Dulay, "Heterogeneous photocatalysis," Chemical Reviews, vol. 93, no. 1, pp. 341-357, 199.

[2]. Noor Idrus. Anodic Oxidation of Titanium InSulphuric Acid $\left(\mathrm{H}_{2} \mathrm{SO}_{4}\right)$ for Biomedical Application [master thesis]. Johor: UniversitiTun Hussein Onn Malaysia, Faculty of Mechanical and Manufacturing Engineering; 2013.

[3]. S.Kathirvelu*, Louis D’Souza, and BhaarathiDhurai, 2008 Nanotechnology Applications in Textiles, Indian Journal of Science and Technology Vol.1 No 5 1:10. 
[4]. Respicio NC, Heitz JR. Comparative Toxicity of Rhodamine B and Rhodamine 6G to the House Fly (Muscadomestica 1.). Bull Environ ContamToxicol. 1981; 27(2): 274-81.

[5]. John Edgar French. Toxicology and Carcinogenesis Studies of Rhodamine 6G,[PhD thesis] Washington:U.S. Department of Health and Human Services Public Health Service National Institutes Of Health;1989.

[6]. M; Gondal MA; Yamani ZH . Removal of Rhodamine 6G Induced by Laser and Catalyzed by Pt/WO3. Nanocomposite Catalysis Communications 2010; 11(8): 768-772.

[7]. TanmayGhorai K; NiladriBiswas. Photodegradation of Rhodamine 6G in Aqueous Solution via SrCrO 4 and TiO2 Nano-sphere Mixed Oxides. Journal of Material Research and Technology, 2013; 2(1): 7-10.

[8]. AshishBansal ${ }^{\mathrm{a}}$,DeependarSharma ${ }^{\mathrm{b}}$, RakshitAmeta ${ }^{\mathrm{c}}$ and HariS. Sharma* ${ }^{*}$. Photodegradation of Rhodamine-6G in Presence of Semiconducting Ammonium Phosphomolybdate. International Journal of Chemical Sciences 2010; 8(4): $2747-2755$.

[9]. Sandip P. Patila, V.S. Shrivastavaa\& G.H. Sonawaneb*. Photocatalytic degradation of Rhodamine 6G using ZnOmontmorillonitenanocomposite: a kinetic approach. Desalination and Water Treatment 2015; 54(2): 374-381.

\section{NOTES:}

[1]. The proposal of the study was approved by the research council of the institute of laser / Sudan University of Science and Technology.

[2]. No animals were used in the study, so there was no need for licenses and approvals from animal ethics committee.

[3]. There wasn't fieldwork in the study.

[4]. We have no competing interests.

[5]. Authors contribution:

- $\quad$ First author: design of the study, results analysis and revision of the manuscript.

- $\quad$ Second author: laboratory work and writing the draft of the manuscript.

[6]. There was no fund from any part. 